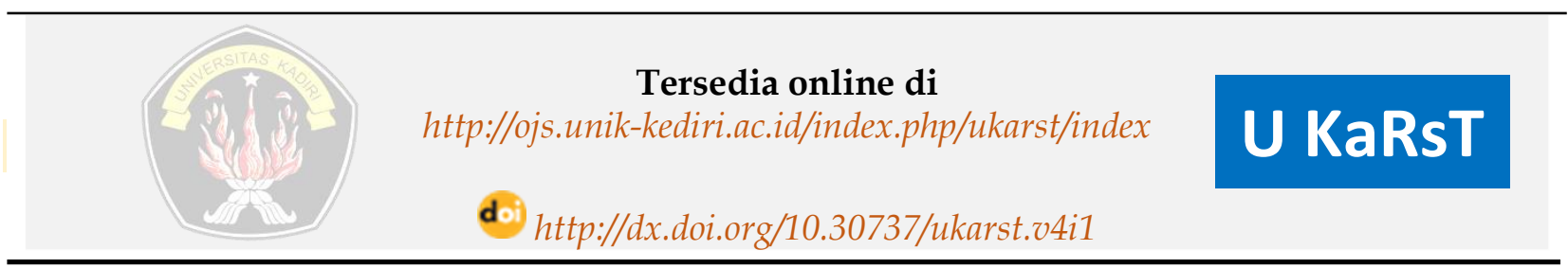

\title{
Penilaian Risiko K3 Konstruksi Dengan Metode Hirarc
}

\author{
I. W. G. E. Triswandana ${ }^{1}$, N. K. Armaeni ${ }^{2}$. \\ 1,2, Fakultas Teknik dan Perencanaan Universitas Warmadewa. \\ email: ${ }^{1}$ ericktriswandana@gmail.com
}

\section{A R T I C L E I N F O}

Artikel History :

Artikel masuk : 30-03-2020

Artikel revisi : 04-04-2020

Artikel diterima : 06-04-2020

Keywords :

SMK3, HIRARC, Risk Identification, Risk Assessment.

\section{Style IEEE dalam mensitasi} artikel ini: [11]

Sanni-anibire, M. O., Mahmoud, A. S., Hassanain, M. A., \& Salami, B. A. A risk assessment approach for enhancing construction safety performance. Safety Science, vol. 121, p 15-29. 2020.

\begin{abstract}
A B S TRA C T
The Work of Building F3 in the Faculty of Medicine, Health Sciences (FKIK) Warmadewa University applied SMK3 to the construction process. Risk identification and assessment have not used the HIRARC method as a basis for mitigation. From this problem, the author considers it necessary to carry out a K3 risk assessment using the HIRARC method to know the potential hazard value of the construction work. Using descriptive quantitative research methods for the approach to risk identification using HIRARC is used to rank each risk. The results of the analysis explained the percentage of high-risk work rankings of each work item including earthworks having a rate of $20 \%$, foundation work by $25 \%$, structural work by $30 \%$, roof work by $31 \%$, finishing work by $25 \%$, electrical work, and plumbing by $12 \%$. While from a total of 65 risks identified, it is known that $25 \%$ risk has a high-risk rating, $43 \%$ risk has a moderate risk rating, and $32 \%$ of threats has a low-risk rating.
\end{abstract}

\section{A B S T R A K}

Pekerjaan Pembangunan Gedung F3 Fakultas Kedokteran Ilmu Kesehatan (FKIK) Universitas Warmadewa menerapkan SMK3 pada proses konstruksinya. Identifikasi dan penilaian risikonya belum menggunakan metode HIRARC sebagai landasan melakukan mitigasi. Dari permasalahan itu, penulis menganggap perlu melakukan assessment risiko K3 menggunakan metode HIRARC dengan tujuan mengetahui potensi nilai bahaya pekerjaan konstruksi tersebut. Menggunakan metode penelitian deskriptif kuantitatif, dilakukan pendekatan terhadap identifikasi risiko menggunakan HIRARC untuk memperoleh peringkat setiap risikonya. Hasil analisis menerangkan besarnya persentase peringkat pekerjaan risiko tinggi dari masing masing item pekerjaan diantaranya pekerjaan tanah memiliki persentase sebesar $20 \%$, pekerjaan pondasi sebesar $25 \%$, pekerjaan struktur sebesar $30 \%$, pekerjaan atap sebesar $31 \%$, pekerjaan finishing sebesar $25 \%$, pekerjaan elektrical dan plumbing sebesar $12 \%$. Sedangkan dari total 65 risiko yang teridentifikasi, diketahui bahwa sebesar $25 \%$ risiko memiliki peringkat tinggi, $43 \%$ memiliki peringkat sedang, dan $32 \%$ memiliki peringkat rendah. 


\section{Pendahuluan}

Kecelakaan adalah suatu kejadian yang tidak direncanakan dan tidak diharapkan yang dapat mengganggu proses produksi/operasi, merusak harta benda/aset, mencederai manusia, atau merusak lingkungan. Kecelakaan tidak selalu menyebabkan luka-luka, tetapi dapat juga menyebabkan kerusakan material dan peralatan yang ada, tetapi kecelakaan yang mengakibatkan luka-luka ini mendapatkan perhatian yang lebih besar[1]. Riset oleh National Safety Council menyatakan bahwa penyebab kecelakaan kerja adalah $88 \%$ akibat unsafe behaviour dimana Perilaku tersebut dapat terjadi karena persepsi juga keyakinan para pekerja yang merasa sudah ahli dibidangnya serta didukung hingga saat ini belum pernah terjadi kecelakaan kerja selama bekerja sehingga tingkat kepedulian untuk bekerja sesuai aturan dan prosedur berkurang[2][3].

Sedangkan, keselamatan kerja merupakan suatu sarana utama untuk mencegah terjadinya kecelakaan kerja yang dapat menimbulkan kerugian berupa luka atau cidera, cacat atau kematian, kerugian harta benda, kerusakan peralatan atau mesin dan kerusakan lingkungan secara luas[4][5]dimana untuk mencegah hal tersebut maka perlu diterapkannya suatu sistem manajemen untuk pengelolaan keselamatan dan kesehatan kerja. seperti ditunjukkan hasil survey pada 100 peringkat atas perusahaan konstruksi di Korea Selatan selama periode tahun 2006-2011 dimana dengan pengimplementasian sistem manajemen keselamatan dan kesehatan kerja mampu mengurangi tingkat kecelakaan kerja hingga 67\% dan mengurangi hingga 10,3\% kecelakaan yang berakibat fatal[6][7]. Jika keselamatan dan kesehatan pekerja terpelihara dengan baik maka angka kesakitan, absensi, kecacatan dan kecelakaan kerja dapat diminimalkan, sehingga akan terwujud pekerja yang sehat dan produktif [8][9].

Karena hal tersebut, perlu diadakannya pengelolaan kesehatan dan keselamatan kerja pada suatu kegiatan maupun proyek konstruksi yang bisa disebut dengan Sistem Manajemen Keselamatan dan Kesehatan Kerja (SMK3) guna mengidentifikasi risiko atau bahaya yang ada pada suatu pekerjaan sehingga risiko tersebut dapat dikendalikan dengan metode-metode yang ada untuk mengurangi maupun mengeliminasi dampaknya. Pada dasarnya K3 adalah upaya mencegah/ menghindari/ mengurangi kecelakaan kerja dengan cara menghentikan/ meniadakan/ menghilangkan resiko (unsur bahaya) guna mencapai target kerja[10]

Pekerjaan Pembangunan Gedung F3 Fakultas Kedokteran dan Ilmu Kesehatan (FKIK) Universitas Warmadewa yang berlokasi di Jl, Terompong No. 24 Tanjung Bungkak, Denpasar Bali adalah proyek yang dibangun untuk menyediakan fasilitas pengajaran umum 
dan audio visual. Proyek ini dibangun diatas lahan seluas 27.2 Are dengan struktur gedung 4 lantai yang didalamnya fasilitas berupa ruang kelas, auditorium audio visual, ruang laboratorium, ruang Focus Group Discussion, dan ruangan utilitas. Pada dasarnya, perusahaan konstruksi pelaksana proyek ini belum memiliki sertifikasi OHSAS 18001 dan seperti yang diketahui bahwa perusahaan yang tersertifikasi memiliki kemampuan lebih baik dalam pengelolaan Sistem Manajemen K3 dan hal tersebut mendukung pendapat bahwa Occupational Health and Safety Management System (OHSMS) memainkan peran strategis yang penting dalam hal kesehatan dan keselamatan di tempat kerja [11][12]. Namun, pada pelaksanaan pengerjaan proyek ini telah menerapkan SMK3 pada proses konstruksinya meskipun belum menggunakan Hazard Identification Risk Analysis and Risk Controlling (HIRARC) sebagai metode penilaian risiko K3 serta acuan dasar untuk melakukan mitigasi terhadap risiko-risiko kerja yang teridentifikasi.

Untuk hal tersebut, maka penulis menganggap perlu melakukan assessment risiko K3 dengan metode HIRARC yang bertujuan untuk mengetahui nilai dari potensi bahaya yang dapat terjadi pada pekerjaan konstruksi tersebut.

\section{Tinjauan Pustaka}

Tema utama keselamatan konstruksi adalah pencegahan kecelakaan. Beberapa penelitian telah dilakukan untuk memberikan wawasan tentang jenis dan penyebab kecelakaan yang melekat dalam industri konstruksi[13]. Beberapa studi telah mempresentasikan tentang penyebab kecelakaan di industri konstruksi Malaysia, dimana studi ini menyimpulkan bahwa penyebab utama kecelakaan konstruksi adalah kelalaian pekerja, kegagalan pekerja untuk mematuhi prosedur kerja, bekerja di tempat tinggi, penggunaan peralatan tanpa alat pengaman, manajemen lokasi yang buruk, lingkungan kerja yang keras, rendahnya pengetahuan dan tingkat keterampilan pekerja, kegagalan untuk menggunakan alat pelindung diri dan sikap pekerja yang meremehkan faktor keamanan[14], sementara studi yang lainnya menyoroti "ditabrak oleh benda-benda yang melesat dan melayang", "ditabrak oleh benda-benda", "benda yang jatuh" dan "disengat oleh sesuatu" sebagai kecelakaan konstruksi yang mayoritas terjadi di Istanbul-Turki[15][16].

Risiko adalah akibat yang kurang menyenangkan (merugikan, membahayakan) dari suatu perbuat atau tindakan[17]. Secara umum Manajemen Risiko didefinisikan sebagai proses, mengidentifikasi, mengukur, memastikan risiko dan mengembangkan strategi untuk mengelola risiko[18]. Dalam mendeteksi semua potensi bahaya kecelakaan kerja perlu adanya identifikasi bahaya dalam setiap aktivitas[19]. 
Melalui identifikasi dan penilaian risiko tersebut dapat diketahui berbagai macam risiko suatu pekerjaan yang kemudian dapat dilakukan berbagai upaya pengendalian untuk mengurangi risiko tersebut agar tidak sampai terjadi kecelakaan[20].

Sedangkan menurut Australia/New Zealand Standards adalah suatu proses yang logis dan sistematis dalam mengidentifikasi, menganalisa, mengevaluasi, mengendalikan, mengawasi, dan mengkomunikasikan risiko yang berhubungan dengan segala aktivitas, fungsi atau proses dengan tujuan perusahaan mampu meminimalisasi kerugian dan memaksimalkan kesempatan. Analisis Risiko Pekerjaan (Task Risk Analysis-TRA) adalah cara menganalisis risiko untuk mengetahui apa saja dan besarnya potensi bahaya yang timbul selama kegiatan berlangsung[21].

Analisis risiko digunakan untuk menganalisis suatu sistem dan merupakan alat yang efisien untuk mengidentifikasi faktor risiko dan mengembangkan strategi untuk mencegah kegagalan. Ini termasuk identifikasi kegagalan, frekuensi dan analisis konsekuensi[22]. Implementasi dari manajemen risiko ini membantu perusahaan dalam mengidentifikasi dan menganalisis risiko sejak awal sehingga membantu membuat keputusan untuk mengatasi risiko tersebut

Maka dapat dikatakan bahwa manajemen risiko adalah suatu upaya dalam menggunakan sumber daya secara efektif untuk mengurangi dampak unsur ketidakpastian dengan penerapan langkah-langkah sistematis dalam mengidentifikasi dan menganalisa suatu permasalahan yang muncul, kemudian dilakukan tindakan pengendalian preventif dengan mentransfer, mengeliminasi, substitusi, maupun dengan rekayasa teknik terhadap suatu permasalahan.

Manajemen risiko K3 berkaitan dengan bahaya dan risiko yang ada di tempat kerja yang dapat menimbulkan kerugian bagi perusahaan[23][24]. Manajemen risiko K3 adalah suatu upaya mengelola risiko dengan sumber daya yang ada untuk mencegah terjadinya suatu kecelakaan kerja yang dilakukan dengan sistematis sesuai dengan standar yang telah ada baik itu nasional maupun internasional.

OHSAS 18001 adalah salah satu standar penerapan manajemen K3 yang dibuat oleh beberapa lembaga sertifikasi kelas dunia seperti British Standard International (BSI) yang bertujuan untuk mencegah terjadinya potensi kecelakaan kerja yang terjadi di lingkungan kerja yang tidak saja akan menimbulkan kerugian secara ekonomis tetapi juga kerugian nonekonomis. Secara umum, OHSAS 18001 merupakan standar internasional dari sistem manajemen keselamatan dan kesehatan kerja. Namun, di kalangan akademis, ada kritik bahwa 
peraturan kesehatan dan keselamatan kerja dapat membatasi terjadinya inovasi dan pengembangan industri dan pada gilirannya, memicu budaya kebencian birokratis[25][26].

Hazard Identification Risk Assessment and Risk Control (HIRARC) merupakan suatu proses pengidentifikasian bahaya yang dapat terjadi baik pada aktifitas rutin amupun non rutin yang kemudian dilakukan proses penilaian berdasarkan bahaya atau risiko yang telah teridentifikasi guna menentukan tinggi rendahnya nilai suatu risiko tersebut sehingga membantu dalam proses pengendaliannya. Pada klausa 4.3.1 pada OHSAS 18001:2007 mengharuskan organisasi/perusahaan yang akan menerapkan SMK3 melakukan penyusunan HIRARC pada perusahaan atau kegiatannya[27]. Dalam penyusunannya HIRARC sendiri dibagi menjadi 3 tahapan diantaranya tahap identifikasi bahaya (hazard identification), tahap penilaian risiko (risk assessment), dan tahap pengendalian risiko (risk control). Dalam tahapan penilaian risiko, dapat digunakan matriks pengendalian risiko standar seperti matriks penilaian risiko AS/NZS 4360 : 2004[28] yang dipakai di standar Australia dan New Zealand dan dapat dilihat pada Tabel 1, 2 dan Tabel 3.

Tabel 1. Skala Probability Pada Standar AS/NZS 4360 : 2004.

\begin{tabular}{ccl}
\hline Tingkat & Kriteria & \multicolumn{1}{c}{ Penjelasan } \\
\hline 1 & Rare & $\begin{array}{l}\text { Mungkin terjadi hanya pada kondisi khusus/ setelah } \\
\text { setahun sekali. }\end{array}$ \\
\hline 2 & Unlikely & $\begin{array}{l}\text { Mungkin terjadi pada beberapa kondisi tertentu, } \\
\text { namun kecil kemungkinan. }\end{array}$ \\
\hline 3 & Posibble & Mungkin terjadi pada beberapa kondisi tertentu. \\
\hline 5 & Likely & Mungkin terjadi pada hampir semua kondisi. \\
\hline 5 & Almost Certainly & Dapat terjadi pada semua kondisi. \\
\hline
\end{tabular}

Sumber : Skala Probability Standar AS/NZS 4360 : 2004.

Tabel 2. Skala Severity Pada Standar AS/NZS 4360 : 2004.

\begin{tabular}{ccl}
\hline Tingkat & Kriteria & \multicolumn{1}{c}{ Penjelasan } \\
\hline 1 & $\begin{array}{c}\text { Insignifican (tidak } \\
\text { bermakna) }\end{array}$ & Tidak ada kerugian, material sangat kecil \\
\hline 2 & Minor (kecil) & $\begin{array}{l}\text { Cidera ringan memerlukan perawatan p2k3 } \\
\text { langsung dapat ditangani di lokasi kejadian, } \\
\text { kerugian material sedang }\end{array}$ \\
\hline 3 & Moderate (sedang) & $\begin{array}{l}\text { Hilang hari kerja, memerlukan perawatan medis, } \\
\text { kerugian material cukup besar. }\end{array}$ \\
\hline 5 & Major (besar) & $\begin{array}{l}\text { Cidera mengakibatkan cacat atau hilang fungsi } \\
\text { tubuh secara total kerugian material besar }\end{array}$ \\
\hline 5 & Extreme & Menyebabkan bencana material sangat besar \\
\hline
\end{tabular}

Sumber: $\quad$ Skala Severity Pada Standar AS/NZS 4360 : 2004. 
Tabel 3. Matriks Penilaian Risiko Standar Australia - New Zealand.

\begin{tabular}{cccccccc}
\hline \multirow{2}{*}{ AS / NZS $\mathbf{4 3 6 0}: \mathbf{2 0 0 4}$} & \multicolumn{9}{c}{ SEVERITY } \\
& Insignificant & Minor & Moderate & Major & Extreme \\
\hline Almost Certainly & Moderate & High & High & V. High & V.High & 5 \\
& Likely & Moderate & Moderate & High & High & V.High & 4 \\
Possible & Low & Moderate & High & High & High & 3 \\
& Unlikely & Low & Low & Moderate & Moderate & High & 2 \\
\hline & Rare & Low & Low & Moderate & Moderate & High & 1 \\
\hline
\end{tabular}

Sumber : Matriks Penilaian Risiko Standar Australia-New Zealand.

Pada Tabel di atas diketahui bahwa subjek penilaian risiko terdiri dari tingkat probabilitas atau kekerapan terjadinya risiko tersebut dan tingkat severity atau keparahan yang diakibatkan apabila risiko tersebut terjadi, dimana apabila 2 subjek tersebut dikalikan maka akan menghasilkan nilai dari suatu risiko yang dapat diklasifikasikan tingkatannya menjadi risiko bernilai rendah (Low) hingga risiko yang bernilai sangat tinggi (Very High).

\section{Metode Penelitian}

Metode penelitian yang digunakan adalah penelitian deskriptif kuantitatif, dimana metode ini mendiskripsikan atau memberi gambaran terhadap objek yang diteliti tanpa membuat kesimpulan yang berlaku untuk umum. Penelitian diawali dengan penyebaran kuesionair identifikasi dan assessment awal bahaya dengan menggunakan sampel top hingga middle management yang diantaranya terdiri dari owner, konsultan pengawas, konsultan perencana, direksi pekerjaan, engineer, supervisor, dan kepala lingkungan perwakilan masyarakat. Kemudian dilakukan penilaian risiko dengan cara mengisi kuisioner yang telah disediakan, hasil dari kuisioner akan ditabelkan untuk selanjutnya diketahui tingkat risiko dari setiap pekerjaan [29]. Analisis yang digunakan yaitu menggunakan pendekatan metode HIRARC (Hazard Identification Risk Assessment and Risk Control) dengan tahapan dimulai dari identifikasi risiko dengan cara menentukan sumber bahaya dari kegiatan-kegiatan yang ditinjau untuk kemudian dilakukan penilaian berdasarkan risiko-risiko yang ada dan dikelompokkan berdasarkan klasifikasinya sehingga dapat dilakukan pengendalian yang tepat sasaran. Namun dalam penelitian ini langkah sistematis dalam penyusunan HIRARC hanya sampai pada penilaian risiko (Risk Assessment). 


\section{Hasil dan Pembahasan}

Berdasarkan studi lapangan dan hasil penelitian diperoleh bahwa pada proyek Pembangunan Gedung F3 Fakultas Kedokteran dan Ilmu Kesehatan Universitas Warmadewa terdapat 3 klasifikasi risiko yang terdiri dari pekerjaan berisiko rendah, sedang, dan tinggi, tetapi tidak teridentifikasi risiko dengan skala nilai sangat tinggi seperti yang dapat dilihat pada ilustrasi Tabel 4.

Tabel 4. Penilaian Risiko dan Peringkat Risiko Berdasarkan Standar AS/NZS 4360 : 2004.

\begin{tabular}{|c|c|c|c|c|c|c|}
\hline No. & Item Pekerjaan & Risiko & $\begin{array}{c}\text { Probability } \\
\text { (P) }\end{array}$ & $\begin{array}{l}\text { Severity } \\
\text { (S) }\end{array}$ & $\begin{array}{c}\text { Scores } \\
(\text { Pxs })\end{array}$ & $\begin{array}{c}\text { Risk } \\
\text { Rating }\end{array}$ \\
\hline D & Pekerjaan Strukt & & & & & \\
\hline \multirow{8}{*}{1} & \multirow{4}{*}{$\begin{array}{l}\text { Pabrikasi } \\
\text { Tulangan }\end{array}$} & $\begin{array}{l}\text { Luka tergores } \\
\text { besi/kawat }\end{array}$ & 4 & 2 & 8 & Moderate \\
\hline & & $\begin{array}{l}\text { Luka tertusuk } \\
\text { besi }\end{array}$ & 3 & 2 & 6 & Moderate \\
\hline & & $\begin{array}{l}\text { Luka tertimpa } \\
\text { material }\end{array}$ & 1 & 2 & 2 & Low \\
\hline & & $\begin{array}{l}\text { Luga terpotong } \\
\text { bar cutter }\end{array}$ & 1 & 2 & 2 & Low \\
\hline & \multirow{4}{*}{$\begin{array}{l}\text { Bongkar dan } \\
\text { pasang bekisting }\end{array}$} & $\begin{array}{l}\text { Luka tergores } \\
\text { besi/kawat }\end{array}$ & 2 & 2 & 4 & Low \\
\hline & & $\begin{array}{l}\text { Luka tertusuk } \\
\text { paku }\end{array}$ & 3 & 2 & 6 & Moderate \\
\hline & & $\begin{array}{l}\text { Luka tertimpa } \\
\text { material }\end{array}$ & 1 & 3 & 3 & Moderate \\
\hline & & $\begin{array}{l}\text { Luka terpukul } \\
\text { palu }\end{array}$ & 4 & 2 & 8 & Moderate \\
\hline \multirow[t]{2}{*}{3} & \multirow{2}{*}{$\begin{array}{l}\text { Bongkar pasang } \\
\text { scafolding }\end{array}$} & $\begin{array}{l}\text { Luka/cidera } \\
\text { akibat pekerja } \\
\text { tertimpa } \\
\text { Formwork } \\
\text { yang runtuh }\end{array}$ & 1 & 5 & 5 & High \\
\hline & & $\begin{array}{l}\text { Luka/cidera } \\
\text { Pekerja jatuh } \\
\text { dari ketinggian }\end{array}$ & 1 & 5 & 5 & High \\
\hline \multirow[t]{2}{*}{4} & \multirow{2}{*}{$\begin{array}{l}\text { Pembersihan } \\
\text { debu dan kotoran } \\
\text { dengan } \\
\text { compressor pada } \\
\text { pekerjaan pelat }\end{array}$} & $\begin{array}{l}\text { Penyakit kulit } \\
\text { dermatitis } \\
\text { akibat debu- } \\
\text { debu dan asap }\end{array}$ & 1 & 2 & 2 & Low \\
\hline & & $\begin{array}{l}\text { Gangguan } \\
\text { pernafasan } \\
\text { akibat debu }\end{array}$ & 1 & 2 & 2 & Low \\
\hline
\end{tabular}


Tabel 4. Penilaian Risiko dan Peringkat Risiko Berdasarkan Standar AS/NZS 4360 : 2004.

\begin{tabular}{|c|c|c|c|c|c|c|}
\hline No. & Item Pekerjaan & Risiko & $\begin{array}{c}\text { Probability } \\
\text { (P) }\end{array}$ & $\begin{array}{l}\text { Severity } \\
\text { (S) }\end{array}$ & $\begin{array}{c}\text { Scores } \\
(\mathbf{P x s})\end{array}$ & $\begin{array}{c}\text { Risk } \\
\text { Rating }\end{array}$ \\
\hline D & Pekerjaan Struk & & & & & \\
\hline \multirow{4}{*}{5} & \multirow{4}{*}{ Pengecoran } & $\begin{array}{l}\text { Pekerja jatuh } \\
\text { dari ketinggian }\end{array}$ & 1 & 5 & 5 & High \\
\hline & & $\begin{array}{l}\text { Iritasi kulit } \\
\text { akibat campuran } \\
\text { kimia beton }\end{array}$ & 1 & 3 & 3 & Low \\
\hline & & $\begin{array}{l}\text { Tertimpa } \\
\text { robohnya } \\
\text { cetakan beton }\end{array}$ & 1 & 5 & 5 & High \\
\hline & & $\begin{array}{l}\text { Luga terpotong } \\
\text { bar cutter }\end{array}$ & 1 & 2 & 2 & Low \\
\hline
\end{tabular}

Sumber : Analisis Data.

Dari Tabel 4. dapat diketahui bahwa pekerjaan struktur memiliki risiko beragam dengan sebaran persentase yang serupa terkait nilai peringkat risiko. Hasil analisis menunjukkan, pekerjaan struktur dan pekerjaan atap memiliki risiko tertinggi dari keseluruhan item pekerjaan dengan persentase dapat dilihat pada Gambar 1. dan Gambar 2.

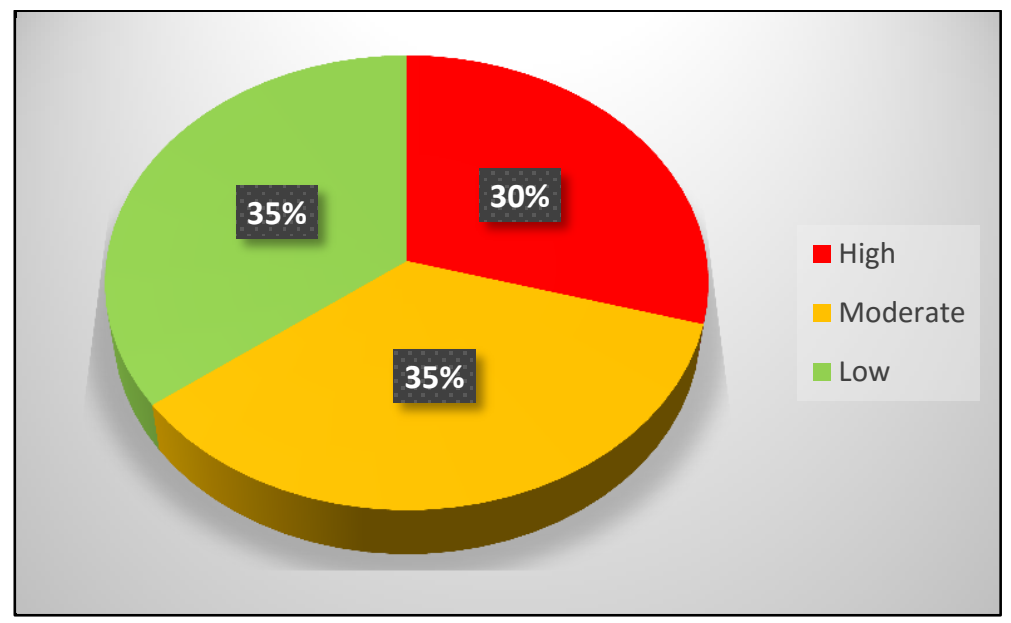

Sumber: Analisis Data.

Gambar 1. Persentase Risk Rating Pada Pekerjaan Struktur. 


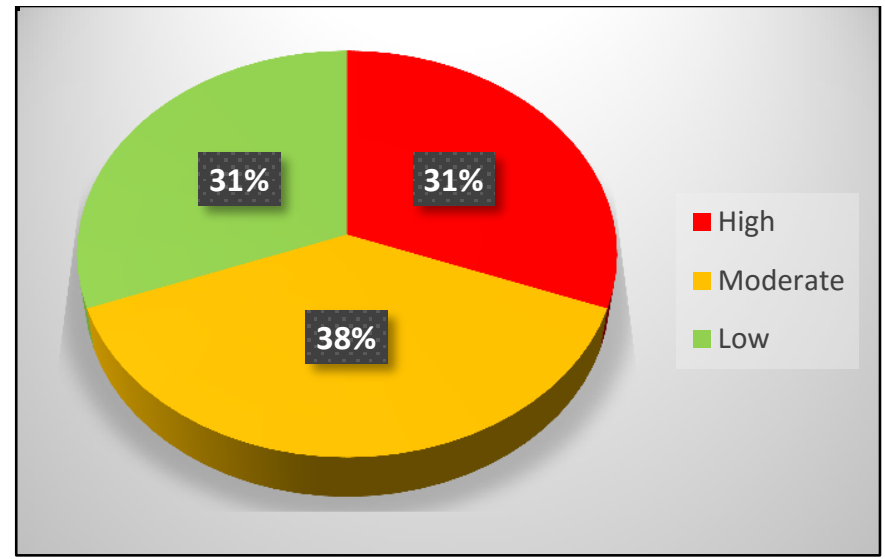

Sumber: Analisis Data.

Gambar 2. Persentase Risk Rating Pada Pekerjaan Atap.

Dari Gambar 1. dan Gambar 2. diketahui bahwa jumlah sebaran pekerjaan dengan tingkat risiko tinggi hampir sama dengan jumlah sebaran pekerjaan dengan tingkat risiko rendah dan sedang, pada pekerjaan struktur, persentase tingkat risiko tinggi adalah sebesar $30 \%$ atau sebanyak 5 risiko dari total 17 risiko yang teridentifikasi. Untuk pekerjaan atap, persentase tingkat risiko tertinggi adalah sebesar $31 \%$ atau sebanyak 4 risiko dari total 14 risiko yang teridentifikasi pada sub item pekerjaan tersebut. Sedangkan untuk total jumlah risiko yang teridentifikasi dalam tahap pengerjaan proyek ini adalah sebanyak 65 risiko dengan persentase tingkat risiko rendah sebesar 32\%, tingkat risiko sedang sebesar $43 \%$, dan tingkat risiko tinggi sebesar 25\% yang dapat di lihat pada Gambar 3.

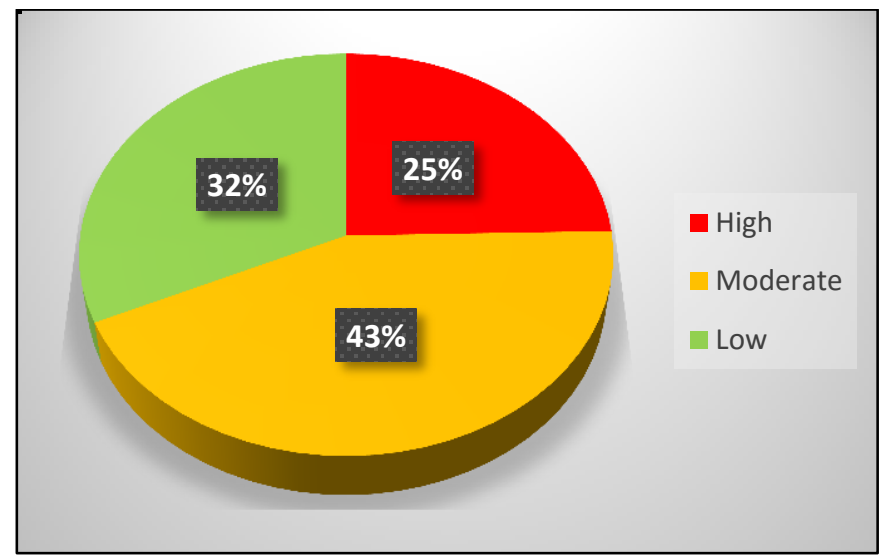

Sumber: Analisis Data.

Gambar 3. Persentase Risk Rating Seluruh Item Pekerjaan.

Dengan diketahui klasifikasi risiko pekerjaan yang terdapat pada Proyek Pembangunan Gedung F3 FKIK Universitas Warmadewa, maka tentunya manajemen proyek dapat melakukan pengendalian dan memitigasi risiko yang ada dengan lebih tepat. 


\section{Simpulan dan Saran}

\subsection{Simpulan.}

Dari hasil analisis dapat disimpulkan bahwa besarnya persentase peringkat dengan risiko tinggi dari masing masing item pekerjaan diantaranya adalah pekerjaan tanah dengan persentase sebesar 20\%, pekerjaan pondasi sebesar 25\%, pekerjaan struktur sebesar $30 \%$, Pekerjaan Atap sebesar 31\%, Pekerjaan Finishing sebesar 25\%, dan Pekerjaan Electrical dan Plumbing sebesar 12\%. Sedangkan dari Total 65 risiko yang teridentifikasi pada sub item pekerjaan yang ada, diketahui bahwa sebesar $25 \%$ risiko yang teridentifikasi tersebut memiliki peringkat risiko tinggi, $43 \%$ risiko yang teridentifikasi memiliki peringkat risiko sedang, dan $32 \%$ dari risiko yang teridentifikasi memiliki peringkat risiko rendah.

\subsection{Saran.}

Dari penelitian yang telah dilakukan untuk mengetahui dan menganalisis risikorisiko yang terjadi, maka disarankan untuk penelitian lebih lanjutnya mengarah ke pengendalian dari risiko yang ada serta melakukan evaluasi terhadap metode penilaian dan pengendaliannya sehingga nantinya dapat dijadikan dasar untuk penerapan sistem keselamatan dan kesehatan kerja di proyek konstruksi. 


\section{Daftar Pustaka}

[1] M. R. A. Simanjuntak and R. Praditya, "IDENTIFIKASI PENYEBAB RISIKO KECELAKAAN KERJA PADA KEGIATAN KONSTRUKSI BANGUNAN GEDUNG DI DKI JAKARTA,” Media Eng., vol. 2, no. 2, pp. 85-99, 2012.

[2] S. Rinawati, "LEVEL OF SAFE BEHAVIOR WITH THE IMPLEMENTATION OF HOT WORK PERMIT APPROACH IN PT BBB EAST JAVA,” J. Vocat. Heal. Stud., vol. 01, pp. 89-96, 2018.

[3] Supriyadi and F. Ramdan, "BOILER MENGGUNAKAN METODE HAZARD IDENTIFICATION RISK ASSESSMENT AND RISK CONTROL ( HIRARC ) Universitas Serang Raya kerja dapat direncanakan, dilakukan dan Identification, Risk Assesment And Risk,” J. Ind. Hyg. Occup. Heal., vol. 1, no. 2, pp. 161-178, 2017.

[4] J. Min, Y. Kim, S. Lee, T. Jang, I. Kim, and J. Song, "The Fourth Industrial Revolution and Its Impact on Occupational Health and Safety, Worker's Compensation and Labor Conditions," Saf. Health Work, vol. 10, no. 4, pp. 400-408, 2019.

[5] P. U. dan P. R. Menteri, "PERATURAN MENTERI PEKERJAAN UMUM DAN PERUMAHAN RAKYAT REPUBLIK INDONESIA NOMOR 02/PRT/M/2018," 2018.

[6] S. J. Yoon, H. K. Lin, G. Chen, S. Yi, J. Choi, and Z. Rui, "Effect of Occupational Health and Safety Management System on Work-Related Accident Rate and Differences of Occupational Health and Safety Management System Awareness between Managers in South Korea' s Construction Industry," Saf. Health Work, vol. 4, no. 4, pp. 201-209, 2013.

[7] F. E. Saputra, "ANALISIS KESESUAIAN PENERAPAN SAFETY SI G N DI PT . TERMINAL PETIKEMAS SURABAYA,” Indones. J. Occup. Saf. Heal., vol. 5, no. 2, pp. 121-131, 2016.

[8] C. D. Yuliandi and E. Ahman, "PENERAPAN KESELAMATAN DAN KESEHATAN KERJA ( K3 ) DI LEMBANG APPLICATION OF WORK SAFETY AND HEALTH ( K3 ) IN THE WORK ENVIRONMENT OF ARTIFICIAL INSEMINATION ( BIB ) LEMBANG,” Manajerial, vol. 18, no. 2, pp. 98-109, 2019.

[9] A. I. Candra, "Pada Pembangunan Gedung Mini Hospital Universitas Kadiri," Ukarst, vol. 1, no. 1, pp. 63-70, 2017. 
[10] A. Nadhir, "PENGARUH PENGELOLAAN KESELAMATAN DAN KESEHATAN KERJA TERHADAP PRODUKTIVITAS KERJA PADA PEKERJAAN KONSTRUKSI GEDUNG DI CV. PILAR BLITAR MAPAN SEJAHTERA," Qua Tek., vol. 7, no. 1, pp. 11-20, 2017.

[11] I. Mohammadfam, M. Kamalinia, M. Momeni, R. Golmohammadi, Y. Hamidi, and A. Soltanian, "Evaluation of the Quality of Occupational Health and Safety Management Systems Based on Key Performance Indicators in Certi fi ed Organizations," Saf. Health Work, vol. 8, no. 2, pp. 156-161, 2017.

[12] A. I. Candra et al., "Pengecekan Kelayakan Bangunan Gedung Sma Negeri 1 Kota Kediri Yang Digunakan Untuk Aktifitas,” vol. 2, no. 2, pp. 108-116, 2019.

[13] M. O. Sanni-anibire, A. S. Mahmoud, M. A. Hassanain, and B. A. Salami, "A risk assessment approach for enhancing construction safety performance," Saf. Sci., vol. 121, no. September 2019, pp. 15-29, 2020.

[14] M. J. Tear, T. W. Reader, S. Shorrock, and B. Kirwan, "Safety culture and power: Interactions between perceptions of safety culture, organisational hierarchy, and national culture," Saf. Sci., vol. 121, no. March 2018, pp. 550-561, 2020.

[15] C. Engineering, “Abdul Rahim Abdul Hamid, Muhd Zaimi Abd Majid, Bachan Singh," vol. 20, no. 2, pp. 242-259, 2008.

[16] F. Yilmaz, "Monitoring and analysis of construction site accidents by using accidents analysis management system in Turkey.” p. 57, 2015.

[17] J. Tjakra, J. E. C. Langi, D. R. O. Walangitan, F. Teknik, J. Sipil, and U. S. Ratulangi, "MANAJEMEN RISIKO KESELAMATAN DAN KESEHATAN KERJA ( K3 ) PADA PROYEK PEMBANGUNAN RUKO ORLENS FASHION MANADO,” J. Sipil Stat., vol. 1, no. 4, pp. 282-288, 2013.

[18] A. Lokobal, "PELAKSANA KONSTRUKSI DI PROPINSI PAPUA ( Study Kasus di Kabupaten Sarmi )," Media Eng., vol. 4, no. 2, pp. 109-118, 2014.

[19] C. Pokphand, P. Martino, D. I. Rinawati, and R. Rumita, “Analisis Identifikasi Bahaya Kecelakaan Kerja Menggunakan Job Safety Analysis ( JSA ) Dengan Pendekatan Hazard Identification, Risk Assessment And Risk Control ( HIRARC )," Ind. Eng., vol. 2, no. 2, pp. 1-9, 2015. 
[20] A. Y. Ambarani and A. R. Tualeka, "HAZARD IDENTIFICATION AND RISK ASSESSMENT ( HIRA ) PADA PROSES FABRIKASI PLATE TANKI 42-T-501A PT PERTAMINA ( PERSERO ) RU VI BALONGAN,"' Indones. J. Occup. Saf. Heal., vol. 5, no. 2, pp. 192-203, 2016.

[21] I. Oditya Putra, "RISK MANAGEMENT AT BIOPHARMACEUTICAL AND PHARMACEUTICAL ANALYSIS LABORATORY OF AIRLANGGA UNIVERSITY,”Indones. J. Occup. Saf. Heal., vol. 7, no. 1, pp. 81-90, 2018.

[22] S. Morsal, Z. Borzooei, and J. Maleki, "An effective approach for assessing risk of failure in urban sewer pipelines using a combination of GIS and AHP-DEA," Process Saf. Environ. Prot., vol. 133, pp. 275-285, 2020.

[23] K. Madill, "Standards Australia,” 2003.

[24] A. I. Candra, "STUDI KASUS STABILITAS STRUKTUR TANAH LEMPUNG PADA JALAN TOTOK KEROT KEDIRI MENGGUNAKAN LIMBAH KERTAS,” UKaRsT, vol. 2, no. 2, p. 11, 2018.

[25] A. R. Hale, D. Borys, and M. Adams, "afety regulation: The lessons of workplace safety rule management for managing the regulatory burden.” pp. 112-122, 2015.

[26] F. Salguero-Caparros, M. C. Pardo-Ferreira, M. Martinez-Rojas, and J. C. RubioRomero, "Management of legal compliance in occupational health and safety . A literature review," Saf. Sci., vol. 121, no. June 2019, pp. 111-118, 2020.

[27] S. A. Series, "Occupational health and safety management systems - Requirements," 2007.

[28] N. Z. Standard, "Risk management," 2004.

[29] A. I. Candra, E. Gardjito, Y. Cahyo, and G. A. Prasetyo, "Pemanfaatan Limbah Puntung Rokok Filter Sebagai Bahan Campuran Beton Ringan Berpori,” UKaRsT, vol. 3, p. 85, 2019 